\title{
Occupational and individual factors in acute shoulder-neck disorders among industrial workers
}

\author{
A BJELlE, ${ }^{1}$ M HAGBERG, ${ }^{2}$ AND G MICHAELSON ${ }^{3}$
}

From the Department of Rheumatology, ${ }^{1}$ Umeå Hospital, the Departments of Occupational Health and Anatomy, National Board of Occupational Safety and Health, and University of Umeå, ${ }^{2}$ and the Health Care Center, ${ }^{3}$ Volvo-Umeverken, Umeå, Sweden

ABSTRACT Twenty workers, consecutively attending the industrial health care centre for the first time with acute shoulder-neck pains, were subject to extensive rheumatological and ergonomic examinations. In seven patients congenital malformations or diseases causing musculoskeletal symptoms, or both, were probable aetiological factors. In the remaining 13 patients a significantly higher load was found on both shoulders (assessed by biomechanical film analysis) than in matched controls. Age, anthropometric measures, muscle strength, or HLAB27 did not appear as significant, predisposing factors. Most patients could return to work within a year.

Symptoms and complaints relating to the shoulderneck region are frequent among industrial workers. ${ }^{1-3}$ Both individual factors, such as constitution, age, or disease, and external factors such as trauma from occupation or other activities are of aetiological importance. ${ }^{5}$ In a previous study of industrial workers with prolonged shoulder pain ${ }^{2}$ the case history of working height with hands at or above acromion height was shown to constitute a significant, occupational factor. Inflammatory rheumatic diseases and aging were other important causes.

The aim of the present investigation was to evaluate the influence of disease and to study the significance of measured individual and occupational factors in acute non-traumatic shoulder-neck pain among industrial workers.

\section{Material and methods}

The methods used for this investigation were approved by the ethical committee of the medical faculty, Umeå University.

\section{PATIENTS}

The first 20 workers ( 17 men, 3 women) at a manufacturing plant who attended the industrial health

Received 29 August 1980

Accepted 23 January 1981 care centre with acute non-traumatic, shoulderneck pain were included in the study. The mean age of the patients was 35 years (SD 13.2).

\section{CONTROLS}

The case-control method was used in this study to evaluate the role of ergonomic factors in acute non-traumatic shoulder-neck disorders. To eliminate confounding factors the controls were selected by paired sampling and individual matching. ${ }^{6}$ Two controls were selected for each patient in whom causative disease or malformation was not found. The controls $(n=26)$ were obtained by paired sampling from employment records. The paired sampling was done with the additional requirements that the workers selected must match the corresponding case in the following criteria: age, sex, and place of work (the controls had to work in the factory halls). Furthermore, the workers selected as controls were not to have consulted the industrial health care centre for shoulder-neck disorders; this was verified by checking the patient records of the workers. From an age-class employment listing, the two workers who satisfied the above defined criteria closest to each patient were selected.

\section{INDUSTRY}

All patients and controls were employed at an industrial plant with 1000 employees in which truck cabins are manufactured and assembled. The main work tasks in the plant are assembling (in standing positions), 
pressing, and welding. The industrial health care centre is staffed by an industrial physician, a physiotherapist, and two nurses.

\section{MEDICAL EXAMINATION}

The patients were examined at the health care centre by the same physician. All patients with acute, non-traumatic, shoulder-neck pains were referred to the outpatient clinic of the rheumatology department. Each patient had to undergo an extensive clinical examination, including local anaesthesia for the definition of pain location. Laboratory tests included serology, serum muscle enzymes, and HLA B27. Exploratory puncture of the glenohumeral joint was performed in patients with tenderness over the joint. Standard radiographs of the cervical spine and both shoulder joints were taken for all patients except the youngest (21 years).

\section{ANTHROPOMETRIC AND ISOMETRIC MUSCLE STRENGTH MEASUREMENTS}

The same day as the medical examination was given to the patients anthropometric measures and isometric muscle strength were also assessed. For the controls the measurements were done during the month immediately after the 20 cases had been examined. Anthropometric measurements consisted of stature, eye-height, acromion height, elbow height, and grip height when standing. Isometric muscle strength (maximal voluntary contraction) on both sides was measured by strain-gauge instruments. The patients and controls were asked to perform their maximal effort and to stop the contraction if pain became very severe. Measurements were made for the following contractions: shoulder elevation at the acromion, abduction and forward flexion of the shoulder joints at the neutral position with the arm at the side, and elbow flexion at $90^{\circ}$ with the arm at the side and the forearm semipronated. Grip strength was measured by a vigorimeter. All 20 patients were right-handed; among the controls data of handedness were not obtained.

\section{ERGONOMIC INVESTIGATION}

Biomechanical analysis-The movements of the arms at work were film-recorded during several work cycles (range: $0 \cdot 5-8$ hours) for both the patients and the controls (fig 1). The film-recordings were made for the patients two to four weeks after the referral to the outpatient clinic of the rheumatology department. By that time the complaints for most of the patients had decreased as an effect of rest (sick leave from work) and treatment (local injections of corticosteroids and oral anti-inflammatory drugs) and seven patients had already returned to work when film recordings were made. The load on the shoulders during work for the patients and the controls was estimated by biomechanical film analysis. This consisted of measuring the duration and the frequency of shoulder abduction or forward flexion of more than $60^{\circ}$. The analyses were done blind by a laboratory assistant.

Electromyography-To measure the load on individual shoulder muscles during assembly work, an electromyographic investigation was made. ${ }^{7}$ In the occupational tasks of three patients EMG recordings were obtained from the three patients and from two healthy volunteers, well trained in the patients' occupational tasks. Bipolar surface electrodes were used for the right descending part of the trapezius muscle and bipolar wire electrodes for the supraspinatus muscle. Telemetric recordings during work were made for at least one hour on a FM-tape recorder (fig 1). Computer analysis of myoelectric amplitude levels was made for muscular load level determination in the descending part of the trapezius muscle during work, using the techniques described by Ericson and Hagberg. ${ }^{8}$ For detection of local muscle fatigue in the supraspinatus muscle, the mean power frequency was used as single estimate of the fatigue state in the muscle. ${ }^{9} 10$

\section{PROGNOSIS}

The number of days on sick leave due to shoulderneck pain for the patients and controls one year after the first visit to the health care centre, were assessed from employment records. The frequency of shoulder neck complaints, change of work tasks, and sick leave due to shoulder or neck pain during the past year were recorded at personal interviews with the

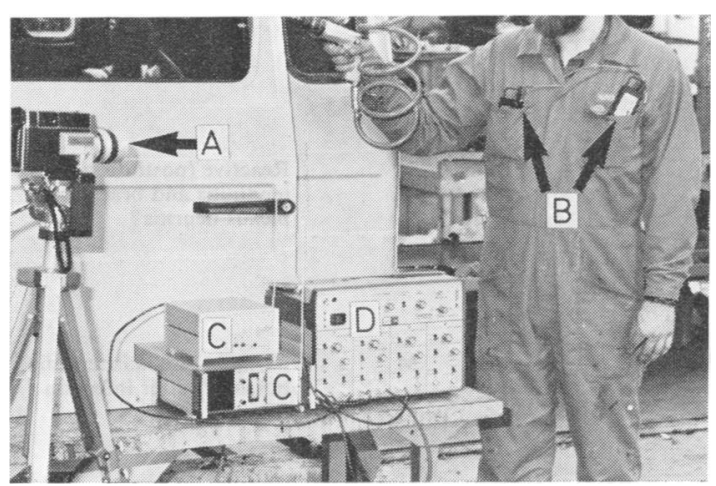

Fig 1 Simplified layout of shoulder load measurement during work. (A) Film camera for registration of arm movements. (B) Preamplifier and transmitter of EMG signals from shoulder and neck muscles. $(C)$ Receiver and amplifier of EMG signals. (D) FM tape recorder of EMG signals. 
patients one year after the first visit to the health care centre.

STATISTICS

Although data such as muscle strength and anthro- pometric measures traditionally conform to parametric description, non-parametric tests were used in the comparisons made between the patients and the controls, since non-parametric tests may be more efficient. ${ }^{11}$ The non-normality of the groups with re-

Table 1 Medical details of seven patients with medical conditions of probable relation to the shoulder or neck symptoms

\begin{tabular}{|c|c|c|c|c|c|}
\hline Case No & Age & Sex & Diagnosis & History and clinical findings & Laboratory and radiological findings \\
\hline 1 & 22 & $\mathbf{M}$ & $\begin{array}{l}\text { Myopathy NOS. Cervical } \\
\text { spina bifida occulta }\end{array}$ & $\begin{array}{l}\text { Diffuse, non-radiating pain of } \\
\text { shoulders at rest, increased } \\
\text { on movements. Tenderness in } \\
\text { both infraspinatus muscles } \\
\text { and right supraspinatus } \\
\text { tendinitis. Range of move- } \\
\text { ments, isometric muscle } \\
\text { strength, and sensibility not }\end{array}$ & $\begin{array}{l}\text { Routine blood test normal. } \\
\text { Persistent increase of aldolase and } \\
\text { creatinine kinase. EMG signs of } \\
\text { bilateral myopathy of deltoid and } \\
\text { infraspinatus muscles. Spina bifida } \\
\text { of } 6 \text { th cervical vertebra on radio- } \\
\text { graphs. Refused muscle biopsy }\end{array}$ \\
\hline
\end{tabular}

Cervical ribs. Reactive (postinfectious) tendinitis?

Rheumatoid arthritis? Calcific subacromial bursitis

Tenosynovitis NOS. Systemic rheumatic or paramalignant disease?

Enteropathic arthritis. Ulcerative proctitis

Reactive (postinfectious) tendinitis and brachial plexus neuritis?

Myalgia (and subacromial bursitis?) after infection strength, and sensibility not reduced

Five months of pain in left shoulder (right handed), radiating to upper arm on movements. Onset two weeks after lower urinary tract infection. Swelling and tenderness of the medial side of left supraclavicular fossa. No radiating pain or radial pulse weakening on provocation Arthralgia without swelling for 10 years in hip-joints. Gradual onset of right shoulder pain at rest, increased at work since 4 months. "Pain-ful arc"syndrome and compression pain of right subacromial bursa

Two months' pain in left shoulder, increased on movements. Bicipital and infraspinatus tendinitis, and tenderness of trapezius and infraspinatus muscles. Paininhibited muscle strength, but no muscle wasting. General feeling of malaise

Ulcerative proctitis for 26 years. Pain at rest, increased at work, in both shoulders for 3 months, onset 3 weeks after exacerbation of proctitis. Arthritis of left wrist and ankle. Bilateral conjunctivitis

Acute non-radiating pain and impaired range of movement of right shoulder two weeks after respiratory tract infection. Tendinitis and wasting of infraspinatus muscle. No muscle weakness or sensibility disturbance

Pain at rest, increased on movements of left shoulder (right-handed) for 1 month, starting 1 week after respiratory tract infection (streptococci) with fever. Tenderness over deltoid, trapezius, and infraspinatus muscles. Painful arcsyndrome. Pain-inhibited muscle strength. Prostatitis
Routine blood tests normal. HLA B27 negative. Bilateral cervical ribs on radiographs, left rib connected to clavicle by a false joint

Rheumatoid factor positive (Rose-Waaler) 1/80. Other blood tests normal. A few drops of highly viscous acellular synovial fluid aspirated from right glenohumeral joint. Subacromial calcifications of both shoulders on radiography

Raised sedimentation rate, ALAT (SGPT), haptoglobin, polyclonal IgA. Increased BSP retention. Other blood tests normal. Reduced disc between 5 th and 6 th vertebra

Raised sedimentation rate and haptoglobin HLA B27 negative. Normal radiographs of neck and shoulders

Re-innervation potentials in righ shoulder muscles on EMG. Muscle enzymes normal. Raised sedimen-

tation rate and haptoglobin. A few drops of normal synovial fluid aspirated from glenohumeral joint. HLA B27 negative. Reduced disc

C6-C7 on radiograph

Routine blood tests normal

including urine tests with cultures. Raised aldolase levels initially.

Normal radiographs. HLA B27 negative 
spect to age, sex, and pain characteristics is another important reason for using non-parametric statistics. Thus in the tables anthropometric measures, biomechanical variables, days of sick leave, and isometric muscle strength are given in medians and range. The Friedman rank test was used ${ }^{12}$ for comparing the 13 patients without causative disease or malformation with the 26 controls. The Wilcoxon-Mann-Whitney test $^{11}$ was used when comparing the above mentioned variables between the two patient groups (patients with causative disease or malformation 7 , patients without 13). The difference in distribution of symptoms in the right and the left shoulder for the two patient groups was tested by Fisher's exact test. ${ }^{12}$

The p-values given, using the Wilcoxon-MannWhitney test or Fisher's exact test, are two tailed. p-Values greater then 0.05 were regarded as nonsignificant. The statistical methods used in the analysis of the EMG recordings are described in previous reports. ${ }^{7} 810$

\section{Results}

In seven patients ( 6 men, 1 woman) various medical conditions were diagnosed as being highly probable, causative factors. These patients will be referred to as "disease" patients. In the remaining 13 patients (11 men, 2 women) no medical condition of aetiological importance was found. The median age of these "non-disease" patients was 25 years (range: 21-62), the median age in the plant was 33 . For the disease patients the median age was 45 (range: 22-53). The median age of all patients was 28 (range: 21-62).

\section{MEDICAL FINDINGS}

Clinical-Among the disease patients, inflammatory rheumatic diseases were found in five, in the other two congenital malformations of the cervical spine were diagnosed (table 1). Symptoms were one-sided and located to the right shoulder in nine of the 13 non-disease patients while only in one case of the disease group (non-significant). In the latter, affection of both shoulders was more frequent (non-significant) than in the non-disease group (table 2). Impairment of the passive abduction and forward flexion of the shoulder joint was found in only two patients, both in the disease group. All but one patient showed muscular tenderness, the most common locations being the upper part of the trapezius and the infraspinatus muscles. Tendinitis was located to the right shoulder in six of the non-disease patients. Left shoulder tendinitis was found in three of the disease patients and in none of the non-disease patients, the difference in frequency of left shoulder tendinitis is significant $(p<0.015)$ between the non-disease and the disease patients. The most common site of tendinitis was the supraspinatus muscle in both patient groups.

Laboratory-The only pathological finding in the 13 non-disease patients was the raised muscle enzymes (aldolase or creatine kinase, or both), aldolase initially raised more than $151 \mathrm{~kat} / \mathrm{l}$ ( + 5 SD) or creatine kinase raised more than 3.6 microkat/l (+6 SD), or both, in eight patients. After two to eight weeks on sick leave, muscle enzymes were at normal levels except in two patients, neither of whom had findings of myopathy or neuropathy in a clinical EMG-investigation. Two of the disease patients had raised serum concentrations of aldolase or creatine kinase, or both (table 1). In the patient with myopathological EMG findings the increase was persistent. For the patient with streptococci infection the increase was transient and the concentration was normal again one month after the first visit to the outpatient clinic.

Radiological-Cervical spine degeneration (osteophytes on the margins of the vertebral bodies or narrowing of the intervertebral spaces, or both) was found in the six oldest patients ( 2 disease patients, 4 non-disease patients), aged 45 or over. The radiographic signs of osteoarthritis (cervical spine degeneration) was not considered as a disease since this is a normal finding with poor correlation to symptoms. ${ }^{3}$ None of the 20 patients had symptoms related to spinal nerve compression. Shoulder joint radiographs showed reduced cartilage of the right acromioclavicular joint for two of non-disease patients (aged 23 and 35). The acromioclavicular joint was not the origin of the pain, however, as judged from the results of intra-articular injections of local anaesthetics.

Table 2 Summary of medical findings and prognosis for the two patients groups, disease and non-disease patients

\begin{tabular}{|c|c|c|c|c|c|c|c|c|c|c|c|c|c|}
\hline & \multirow[t]{3}{*}{ No } & \multicolumn{2}{|l|}{ Age } & \multicolumn{3}{|c|}{ Side of pains } & \multirow{2}{*}{\multicolumn{2}{|c|}{$\begin{array}{l}\text { Side of } \\
\text { tendinitis }\end{array}$}} & \multirow{3}{*}{$\begin{array}{l}\text { Muscle } \\
\text { enzyme } \\
\text { increase }\end{array}$} & \multicolumn{2}{|c|}{ Days of sick leave } & \multirow{3}{*}{$\begin{array}{l}\text { Working at } \\
\text { present time }\end{array}$} & \multirow{3}{*}{$\begin{array}{l}\text { Shoulder-neck } \\
\text { complaints at } \\
\text { present time }\end{array}$} \\
\hline & & \multirow{2}{*}{$\overline{M e d i a n}$} & \multirow{2}{*}{ Range } & \multirow{2}{*}{ Right } & \multirow{2}{*}{ Left } & \multirow{2}{*}{$\overrightarrow{\text { Both }}$} & & & & Median & Range & & \\
\hline & & & & & & & Right & Left & & & & & \\
\hline Disease & 7 & 45 & $22-53$ & 1 & 2 & 4 & 3 & 3 & 2 & 74 & $29-238$ & 5 & 3 \\
\hline Non-disease & 13 & 25 & $21-62$ & 9 & 1 & 3 & 6 & 0 & 8 & 51 & $12-151$ & 13 & 8 \\
\hline
\end{tabular}


ANTHROPOMETRY AND ISOMETRIC MUSCLE STRENGTH

The anthropometric data were not significantly different, neither between the non-disease patients and the controls nor between the disease and the non-disease patients (table 3). The data were similar to a sample of Swedish industrial workers. ${ }^{13}$ In the isometric muscle strength test the controls were significantly stronger in six of 14 tests compared with the non-disease patients. The latter group, however, was stronger in isometric grip strength test on the left side (table 4). There was no significant difference in isometric muscle strength between the non-disease and disease patients.

\section{ERGONOMIC EVALUATION}

Biomechanics-All non-disease patients and four of the disease patients had work tasks demanding a position with their hands at or above acromion height. Film recordings were not made of three patients since the work tasks were changed during their sick leave. The non-disease patients had a significantly longer duration and higher frequency of abduction or forward flexion in the right and left

Table 3 Anthropometric measurements in standing posture for the shoulder-neck patients and the controls. The units are centimetres $(\mathrm{cm})$ and kilograms $(\mathrm{kg})$

\begin{tabular}{|c|c|c|c|c|c|c|}
\hline & \multicolumn{2}{|c|}{ Disease patients } & \multicolumn{2}{|c|}{ Non-disease patients } & \multicolumn{2}{|c|}{ Controls to non-disease patients } \\
\hline & Median & Range & Median & Range & Median & Range \\
\hline Stature $(\mathrm{cm})$ & $171 \cdot 4$ & $165 \cdot 9-190 \cdot 8$ & $175 \cdot 2$ & $159 \cdot 4-189 \cdot 5$ & $174 \cdot 4$ & $155 \cdot 3-185 \cdot 0$ \\
\hline Eye height (cm) & $160 \cdot 8$ & $154 \cdot 4-176 \cdot 6$ & $163 \cdot 6$ & $149 \cdot 0-177 \cdot 0$ & $162 \cdot 0$ & $145 \cdot 1-175 \cdot 8$ \\
\hline Acromion height (cm) & $141 \cdot 2$ & $137 \cdot 2-152 \cdot 6$ & $142 \cdot 5$ & $128 \cdot 9-154 \cdot 6$ & $144 \cdot 5$ & $125 \cdot 5-150 \cdot 8$ \\
\hline Olecranon height $(\mathrm{cm})$ & $103 \cdot 1$ & $98 \cdot 6-113 \cdot 5$ & $106 \cdot 8$ & $95 \cdot 0-115 \cdot 6$ & $105 \cdot 5$ & $93 \cdot 3-118 \cdot 4$ \\
\hline Grip height (cm) & $73 \cdot 8$ & $71 \cdot 8-82 \cdot 7$ & $75 \cdot 8$ & $65 \cdot 5-82 \cdot 8$ & $77 \cdot 3$ & $66 \cdot 9-80 \cdot 2$ \\
\hline Body weight (kg) & $81 \cdot 4$ & $70 \cdot 0-94 \cdot 0$ & $75 \cdot 2$ & $50 \cdot 5-91 \cdot 8$ & $74 \cdot 8$ & $50 \cdot 7-92 \cdot 0$ \\
\hline
\end{tabular}

Table 4 Isometric muscle strength for shoulder-neck patients and controls. The units are newtons $(N)$, newtonmetres $(\mathrm{Nm})$ and kilopaxals $(k \mathrm{~Pa})$

\begin{tabular}{|c|c|c|c|c|c|c|c|c|}
\hline \multirow[t]{2}{*}{$\begin{array}{l}\text { Isometric } \\
\text { measure }\end{array}$} & & \multicolumn{2}{|c|}{ Disease patients } & \multicolumn{2}{|c|}{ Non-disease patients } & \multicolumn{2}{|c|}{$\begin{array}{l}\text { Controls to non-disease } \\
\text { patients }\end{array}$} & \multirow{2}{*}{$\begin{array}{l}\text { Sign of difference } \\
\text { between controls } \\
\text { and non-disease }\end{array}$} \\
\hline & & Median & Range & Median & Range & Median & Range & \\
\hline \multirow[t]{2}{*}{ Elevation (N) } & $\mathbf{R}$ & 563 & $424-991$ & 712 & $187-870$ & 776 & $257-1200$ & $\mathrm{p}<0.05$ \\
\hline & $\mathbf{L}$ & 584 & $326-981$ & 680 & $135-1001$ & 729 & $246-1140$ & NS \\
\hline \multirow[t]{2}{*}{ Abduction (Nm) } & $\mathbf{R}$ & $96 \cdot 8$ & $45 \cdot 1-117 \cdot 2$ & $93 \cdot 8$ & $21 \cdot 9-136 \cdot 7$ & $114 \cdot 5$ & $69 \cdot 2-189 \cdot 9$ & NS \\
\hline & $\mathbf{L}$ & 86.8 & $40 \cdot 3-118 \cdot 4$ & $94 \cdot 8$ & $19 \cdot 4-158 \cdot 8$ & $115 \cdot 6$ & $63 \cdot 5-180 \cdot 6$ & NS \\
\hline Forward & $\overrightarrow{\mathbf{R}}$ & $83 \cdot 2$ & $38 \cdot 9-114 \cdot 7$ & $104 \cdot 2$ & $21 \cdot 9-136 \cdot 7$ & $110 \cdot 8$ & $40 \cdot 3-196 \cdot 9$ & $\mathrm{p}<0.05$ \\
\hline flexion $(\mathrm{Nm})$ & L & $88 \cdot 1$ & $36 \cdot 5 \cdot 120 \cdot 2$ & $112 \cdot 1$ & $21 \cdot 9-139 \cdot 9$ & 106.9 & $40 \cdot 3-148 \cdot 2$ & NS \\
\hline Outward & $\mathbf{R}$ & $33 \cdot 0$ & $20 \cdot 9-39 \cdot 0$ & $27 \cdot 0$ & $10 \cdot 5-49 \cdot 0$ & $36 \cdot 3$ & $21 \cdot 3-71 \cdot 4$ & $\mathrm{p}<0.025$ \\
\hline rotation $(\mathrm{Nm})$ & $\mathrm{L}$ & $31 \cdot 8$ & $21 \cdot 5-41 \cdot 7$ & $31 \cdot 1$ & $10 \cdot 5-47 \cdot 6$ & $33 \cdot 9$ & $19 \cdot 3-81 \cdot 5$ & $p<0.01$ \\
\hline Inward & $\vec{R}$ & 28.9 & $18 \cdot 9-46 \cdot 6$ & $26 \cdot 4$ & $9 \cdot 3-77 \cdot 2$ & $62 \cdot 6$ & $19 \cdot 2-100 \cdot 0$ & $\mathrm{p}<0.001$ \\
\hline rotation $(\mathrm{Nm})$ & $\mathrm{L}$ & $32 \cdot 3$ & $19 \cdot 1-46 \cdot 6$ & $31 \cdot 2$ & $13 \cdot 4-69 \cdot 1$ & $60 \cdot 0$ & $26 \cdot 8-102 \cdot 0$ & $\mathrm{p}<0.005$ \\
\hline Elbow & $\mathbf{R}$ & $64 \cdot 5$ & $28 \cdot 0-92 \cdot 5$ & $79 \cdot 2$ & $13 \cdot 0-133 \cdot 4$ & $82 \cdot 4$ & $45 \cdot 2-108 \cdot 9$ & NS \\
\hline flexion $(\mathrm{Nm})$ & $\mathrm{L}$ & $64 \cdot 1$ & $37 \cdot 8-94 \cdot 9$ & 80.6 & $13 \cdot 4-114 \cdot 0$ & $75 \cdot 9$ & $42 \cdot 8-104 \cdot 6$ & NS \\
\hline Grip strength & $\mathbf{R}$ & $79 \cdot 5$ & $66 \cdot 7-145 \cdot 3$ & $90 \cdot 3$ & $64 \cdot 7-137 \cdot 5$ & $86 \cdot 2$ & $30 \cdot 4-130 \cdot 3$ & NS \\
\hline$(\mathrm{kPa})$ & L & 76.6 & $51 \cdot 1-139 \cdot 4$ & $90 \cdot 3$ & $65 \cdot 7-159 \cdot 1$ & $92 \cdot 1$ & $60 \cdot 8-119 \cdot 6$ & $\mathrm{p}<0.025$ \\
\hline
\end{tabular}

$\mathbf{R}=\mathbf{R i g h t}$ side. $\mathbf{L}=$ Left side.

Table 5 Biomechanic measurements for shoulder-neck patients and controls

\begin{tabular}{|c|c|c|c|c|c|c|c|c|}
\hline \multirow[t]{2}{*}{$\begin{array}{l}\text { Biomechanic } \\
\text { variables }\end{array}$} & & \multicolumn{2}{|c|}{ Disease patients } & \multicolumn{2}{|c|}{ Non-disease patients } & \multicolumn{2}{|c|}{$\begin{array}{l}\text { Controls to non-disease } \\
\text { patients }\end{array}$} & \multirow{2}{*}{$\begin{array}{l}\text { Sign of difference } \\
\text { between controls } \\
\text { and non-disease }\end{array}$} \\
\hline & & Median & Range & Median & Range & Median & Range & \\
\hline $\begin{array}{l}\text { Duration of } \\
\text { abduction or }\end{array}$ & $\mathbf{R}$ & 1.09 & $0 \cdot 57-2 \cdot 29$ & 1.03 & $0 \cdot 78-1 \cdot 96$ & 0.52 & $0 \cdot 02-1 \cdot 14$ & $\mathrm{p}<0.005$ \\
\hline $\begin{array}{l}\text { forward flexion } \\
\text { (hours/work day) }\end{array}$ & L & 0.95 & $0 \cdot 03-1 \cdot 60$ & $1 \cdot 22$ & $0 \cdot 48-1 \cdot 76$ & 0.51 & $0 \cdot 05-2 \cdot 58$ & $\mathrm{p}<0.025$ \\
\hline $\begin{array}{l}\text { Frequency of } \\
\text { abduction or }\end{array}$ & $\mathbf{R}$ & 1505 & $639-2259$ & 1258 & $823-1722$ & 639 & $59-1573$ & $\mathrm{p}<0.001$ \\
\hline $\begin{array}{l}\text { forward flexion } \\
\text { (times/work day) }\end{array}$ & $\mathbf{L}$ & 833 & $39-1552$ & 1096 & $362-1693$ & 498 & $59-1433$ & $p<0.005$ \\
\hline $\begin{array}{l}\text { Work cycle time } \\
\text { (minutes) }\end{array}$ & & - & - & 9 & $0 \cdot 35-24$ & 12 & $0 \cdot 50-480$ & NS \\
\hline
\end{tabular}

$\mathbf{R}=$ Right side. $\mathrm{L}=$ Left side. 


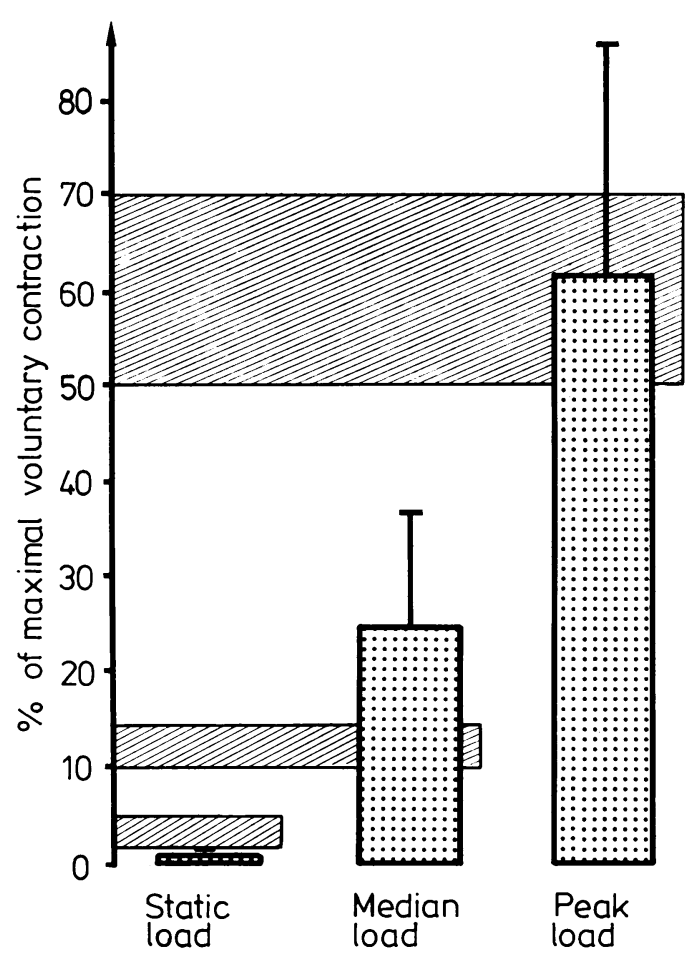

Fig 2 Burs indicate mean value $(+1 S D)$ of static, median, and peak load of descending part of trapezius muscle during one hour of a work day for five assemblers. Shaded zones indicate threshold levels above which static, median, and peak loads, respectively, should not exceed in continuous work, as suggested by Jonsson. ${ }^{14}$

shoulder compared with their controls (table 5). These measurements were not significantly different between the non-disease and the disease patients.

Electromyography-In assembly work there was no static load on the descending part of the trapezius muscle during one-hour work recordings (fig 2). Nevertheless, the median muscular load exceeded the levels recommended by Jonsson. ${ }^{14}$ The supraspinatus muscle showed a significant change of the mean power frequency $(\mathrm{p}<0.05$, two-tailed $t$-test see Hagberg ${ }^{10}$ ) towards lower levels, indicating a fatiguing muscular process for four of the five investigated assemblers during work.

SICK LEAVE AND PROGNOSIS

The median number of days on sick leave in the oneyear follow-up was 51 days (range: 12-238), for the disease group was $74(29-238)$, and for the nondisease group $51(12-151)$. The difference was not significant. The controls had a median of only seven days' (range: 0-62) sick leave, this was significantly $(\mathrm{p}<0.001)$ different from the non-disease patients. Complaints concerning the shoulder-neck region were present in the one-year follow-up in three of the disease patients and in eight of the non-disease patients. All non-disease patients are at the present time working, but nine have transferred to easier (less shoulder load) work. Two of the disease patients are still on sick leave, and another two patients have been transferred to less heavy work.

\section{Discussion}

The exposure in the form of the load on the shoulderneck during work was of particular interest in this study. Shoulder-neck strain is probably a complex effect of many factors including load, load variation with time, localised muscle fatigue, and duration of strain. Exposure is usually considered as the product of quantity and time. In this study, however, it was possible only to evaluate exposure as the load on the shoulder and neck during one work day. The rapid change of work tasks in the industry (new truck cabins are introduced every year or every other year) inhibited further analysis of time effects on shoulder-neck load. The matching factor of place of work (factory hall) for the controls is related to both the exposure and to the disease (shoulder-neck pain). Thus the matching will tend to reduce differences between the cases and the controls, but it is motivated by the need to reduce confounding and to increase the validity of differences found between the cases and the controls. 15

The biomechanical evaluation of the load on the shoulder and neck gives a measure of torque in the glenohumeral joint. Torque is maximal with a right angle in the shoulder joint; with an angle of $60^{\circ}$ the load is still $87 \%$ of the maximal load produced by the weight of the arm. The duration and the frequency of flexion or abduction of more than $60^{\circ}$ in the shoulder joint during work will thus reflect the load on the shoulder and neck produced by lifting the arm. ${ }^{16}$ This load exceeds $10 \%$ of the maximal voluntary torque that can be produced in the shoulder joint. ${ }^{10}$ Film analysis of arm movements does not disclose the effects of handling material or machinery and of pushing and pulling. The EMG recordings thus provide a better measure of the load on the shoulder and neck. High loads on the shoulderneck aggregate can be produced also without abduction or forward flexion of the arm - that is, in sitting-working postures. ${ }^{17} \mathrm{~A}$ careful analysis of each specific operation, however, is necessary. A more active approach to possible ergonomic factors in the make-up of patients with shoulder-neck complaints is thus an essential task of the industrial health care centres. 
Cumulative ischaemic trauma may be the important aetiological factor related to the exposure (high load on the shoulder and neck during work). The transient elevation of muscle enzymes found in the patients indicates hypoxia effect on the muscular tissue. ${ }^{18}$ Furthermore, the EMG findings of mean power frequency decrease in the supraspinatus muscle supports the idea of hypoxia effects, since decrease of the myoelectric power spectra is probably the result of a decrease in the conduction velocity of the muscle fibres due to ischaemic effects. ${ }^{19}$ EMG signs of muscle fatigue have been reported to develop within a minute in the supraspinatus and in the descending part of the trapezius muscles when the arm is raised to a right-angle position..$^{10} \mathrm{~A}$ consistent fatigue of the supraspinatus muscle from work has also been shown in over-head welding. ${ }^{20}$ Besides the higher load on the shoulders, the non-disease patients also lifted their arms more often than their controls. The importance of repetitive muscle contractions for symptoms of tendinitis is supported by experimental data. ${ }^{21}$

The median age of the non-disease patients compared with the median age among the industrial workers at the plant did not indicate age as an important factor. This finding was contrary to previous reports on chronic shoulder pain in which high age was of significant importance. ${ }^{22}$ Anthropometric measures were not of importance, neither in the present material of acute shoulder-neck symptoms nor among workers with prolonged shoulder pains. ${ }^{2}$ The controls were stronger than the non-disease patients in all the muscle strength tests except in the grip strength test. The latter is probably least influenced by pain inhibition due to shoulderneck disorders, and no evidence that low muscular strength was an important factor in shoulder-neck pain was thus found.

The findings of inflammatory diseases and malformations in one-third of the patients with acute shoulder pains among a group of industrial workers is higher than reported earlier. ${ }^{123}$ The disease patients seemed to have more extensive and pronounced local symptoms than were found in the non-disease group, although this difference was of little guidance in the diagnosis of the individual case. Higher sick-leave rates are probably one effect of the more pronounced local symptoms among the disease patients. When comparing the measurements of the shoulder load with the non-disease patients ergonomic factors were also indicated in the disease group. Symptoms from tendons, muscles, and other soft tissues are common, although often neglected symptoms in arthritic conditions. ${ }^{24-27}$ Extended knowledge, however, is necessary to prove conclusively the relation between reactions in the musculoskeletal tissues and diseases, among which infections are of particular interest. 2829

Ergonomic factors probably also modify symptoms of rheumatic diseases and may contribute to their early detection. ${ }^{30}$ Disease and malformation thus merit higher attention in the clinical situation of the industrial health care. Furthermore, these medical factors must be carefully excluded in future studies of ergonomic causes of shoulder complaints in the industry. Terminology like "occupational cervicalbrachial disorders" 31 should be applied with caution and further interdisciplinary investigations encouraged.

This investigation was supported by grants from the Swedish Work Environment Fund.

Requests for reprints to: Dr Mats Hagberg, Work Physiology Division, Box 6104, S-900 06 Umeá.

\section{References}

1 Anderson JAD. Rheumatism in industry: a review. Br J Ind Med $1971 ; 28: 103-21$.

2 Bjelle A, Hagberg M, Michaelson G. Clinical and ergonomic factors in prolonged shoulder pain among industrial workers. Scand J Work Environ Health 1979; 5:205-10.

${ }^{3}$ Hult L. Cervical, dorsal and lumbar spinal syndromes. Acta Orthop Scand 1954; suppl 17.

${ }^{4}$ Booth RE, Marvel JP. Differential diagnosis of shoulder pain. Orthop Clin North Am 1975;6:353-79.

${ }^{5}$ Luopajärvi T, Kuorinka I, Virolainen M, Holmberg M. Prevalence of tenosynovitis and other injuries of the upper extremities in repetitive work. Scand $J$ Work Environ Health 1979;suppl 3:48-55.

- MacMahon B, Pugh TF. Epidemiology principles and methods. Boston: Little, Brown and Company, 1970: 241-82.

${ }^{7}$ Hagberg M. The amplitude distribution of surface EMG in static and intermittent static muscular performance. Eur J Appl Physiol 1979;40:265-72.

8 Ericson B-E, Hagberg M. EMG-signal versus external force: A methodological study on computer aided analysis. In : Asmussen E, Jørgensen K, eds. Biomechanics VI. Baltimore: University Park Press, 1978:251-5.

${ }^{9}$ Lindström L, Kadefors R, Petersén I. An electromyographic index for localized muscle fatigue. J Appl Physiol 1977;43:750-4.

10 Hagberg M. Electromyographic signs of shoulder muscular fatigue in two elevated arm positions. Am J Phys Med 1981;60:111-21.

11 Wonnacott TH, Wonnacott RJ. Introductory statistics. 2nd ed. New York: Wiley \& Sons, 1972:397, 404-7.

12 Brownlee KA. Statistical theory and methodology in science and engineering. 2nd ed. New York: Wiley \& Sons, 1965:163-6, 260-2.

13 Engdal S. Anthropometric measurements. Report 29. Stockholm: Swedish Furniture Research Institute, 1974.

14 Jonsson B. Kinesiology. In: Cobb WA, Van Duijn H, eds. Contemporary clinical neurophysiology. EEG suppl No 34. Amsterdam: Elsevier Scientific Publishing Company, 1978.

15 Miettinen OS. Matching and design efficiency in retro- 
spective studies. Am J Epidemiol 1970;91:111-8.

16 Inman VT, Saunders JB, Abbott LC. Observations on the function of the shoulder joint. J Bone Joint Surg 1944; 26A:1-30.

17 Jonsson B, Hagberg M, Sima S. Vocational electromyography in shoulder muscles in an electronic plant. In: Fidelus K, ed. Biomechanics VII. Baltimore: University Park Press (in press)

18 Fojt E, Ekelund L-G, Hultman E. Enzyme activities in hepatic venous blood under strenuous physical exercise. Pflügers Archiv 1976;361:287-96.

19 Mortimer JT, Magnusson R, Petersén I. Conduction velocity in ischemic muscle: effect on EMG frequency spectrum. Am J Physiol 1970;219:1324-9.

${ }^{20}$ Herberts P, Kadefors R. A study of painful shoulder in welders. Acta Orthop Scand 1976;47:381-7.

${ }^{21}$ Rais O. Peritenomyosis (peritendinitis) crepitans acuta. Acta Chir Scand 1961 ;suppl 268.

22 Wright V, Haq AMMM. Periarthritis of the shoulder: I Aetiological considerations with particular reference to personality factors. Ann Rheum Dis 1976;35:213-9.

${ }^{23}$ Hult L. The Munkfors investigation. Acta Orthop Scand 1954 ; suppl 16.

${ }^{24}$ Bjelle A, Hofer PA, Sjöström M. Myopathy of proximal muscles in arthritic patients. In: Feltkamp B, ed. Nonarticular forms of rheumatoid arthritis. Leiden: Stafleus Scientific Publ Co, 1977:129-40.

${ }^{25}$ Bjelle A. Syndromes of reactive arthritis in Northern Sweden. In: Dumonde DC, Maini RA, eds. Current research in rheumatoid arthritis and allied diseases. Lancaster: MTP Press (in press).

${ }^{26}$ Bywaters EGL. Lesions of bursae, tendons and tendon sheaths. Clinics in Rheumatic Diseases 1979;5:883-925.

25 Reza MJ. Verity MA. Neuromuscular manifestations of rheumatoid arthritis: A clinical and histomorphological analysis. Clinics in Rheumatic Diseases 1977;3:565-88.

${ }^{28}$ Dumonde DC, Steward MW. The role of microbial infection in rheumatic disease. In: Scott JT, ed. Copeman's textbook of the rheumatic diseases. 5th ed. Edinburgh: Churchill Livingstone, 1978:222-58.

${ }^{29}$ Friman G. Effect of acute infections disease on human isometric muscle endurance. Ups J Med Sci 1978;83: 105-8.

${ }^{30}$ Anderson JAD. Occupation as a modifying factor in the diagnosis and treatment of rheumatic diseases. Curr Med Res Opin 1974;2:521-8.

${ }^{31}$ Maeda K. Occupational cervicobrachial disorder and its causative factors. J Hum Ergol 1977;6:193-202. 